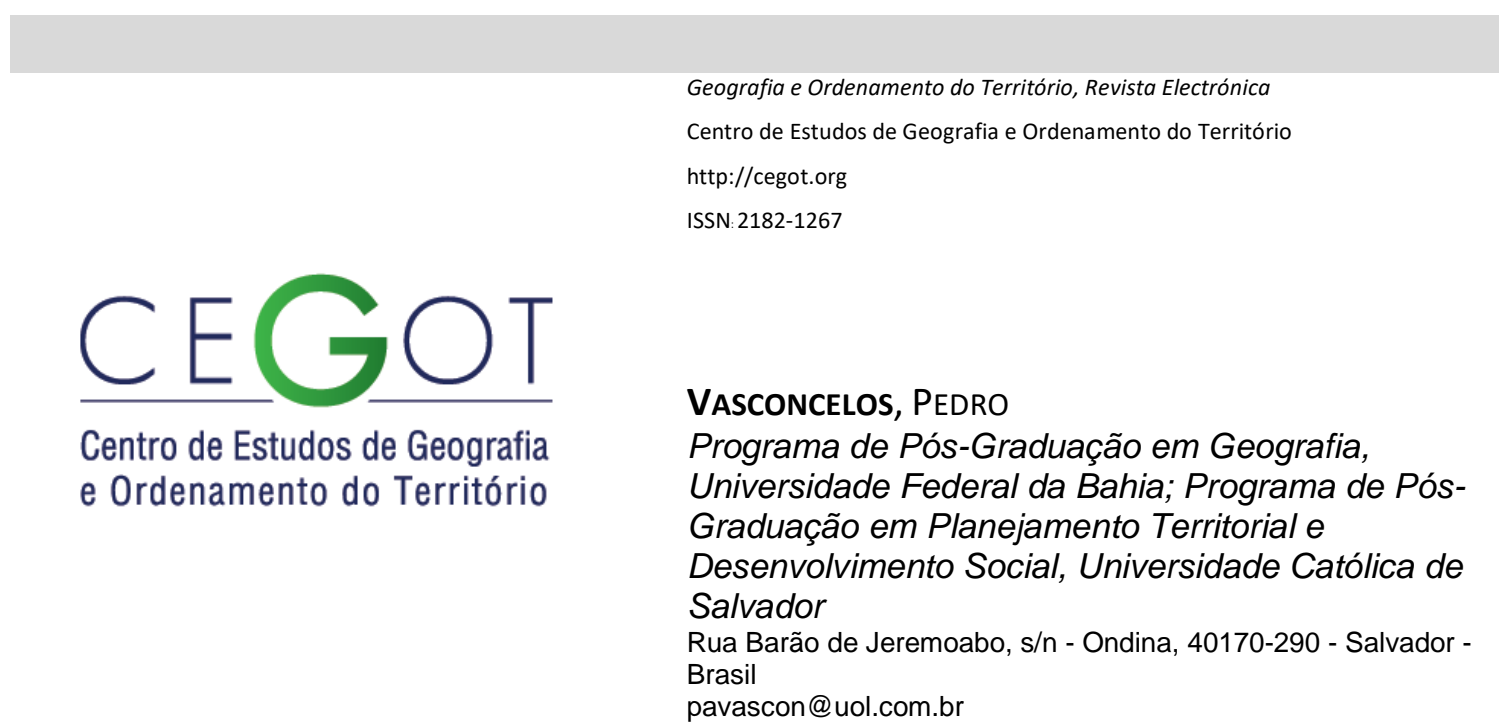

\title{
De redes a territórios: o Império colonial português
}

\author{
From networks to territories: the Portuguese Colonial Empire
}

Referência: Vasconcelos, Pedro (2016). De redes a territórios: o Império colonial português. Revista de Geografia e Ordenamento do Território (GOT), n. 10 (dezembro). Centro de Estudos de Geografia e Ordenamento do Território, p. 35-54, dx.doi.org/10.17127/got/2016.10.002

\section{RESUMO}

O objetivo do artigo é o de levantar questões geográficas para entender a integração do território brasileiro no Império colonial português. A "descoberta" do Brasil fez parte de uma progressão imperial portuguesa que estava voltada para a busca de especiarias e para o estabelecimento de monopólios comerciais, o que resultou na implantação de uma rede de fluxos marítimos apoiada em portos e fortificações ao longo da rota entre Lisboa e as Índias. A colonização do território brasileiro, com sua enorme extensão geográfica, obrigou os portugueses a adotar outra lógica, a territorial e ao mesmo tempo encontrar uma atividade econômica para manter a nova colônia. O texto é dividido em duas partes: na primeira é examinada a situação do Brasil no contexto do Império colonial português, e em seguida são analisados, de forma resumida, os papéis do Estado e da Igreja Católica durante o período colonial no Brasil.

Palavras-chave: rede; território; Império Colonial Português

\section{ABSTRACT}

The objective of this article is to raise geographical issues to understand the integration of Brazil in the Portuguese Colonial Empire. The "discovery" of Brazil was part of the Portuguese imperial expansion that was focused on the search for spices and for the establishment of commercial monopolies, which resulted in the establishment of a network 
of marine flows supported by ports and fortifications along the route between Lisbon and the Indies. The colonization of Brazil, with its huge geographical extent, forced the Portuguese to adopt different territorial logic and at the same time finding an economic activity to keep the new colony. The text is divided into two parts: the first examines the situation of Brazil in the Portuguese Colonial Empire, and in the second, the roles of the State and the Catholic Church during the colonial period in Brazil are analyzed briefly.

Keywords: network; territory; Portuguese Colonial Empire

O objetivo deste artigo $^{1}$ não é o de avaliar o passado colonial português, nem de fazer uma crítica do processo colonizador, mas o de levantar questões geográficas para entender a integração do território brasileiro no Império colonial português.

Uma questão preliminar é sobre a tradição historiográfica de examinar o Brasil de forma separada do Império português² ou de discutir apenas a relação bilateral colônia/metrópole. A Geografia Histórica, dando ênfase ao espaço, pode trazer uma visão mais ampliada, com destaque aos antecedentes e experiências efetuadas pelos portugueses, antes mesmo da colonização do território brasileiro.

De fato, a "descoberta" do Brasil fez parte de uma progressão imperial portuguesa que estava voltada para a busca de especiarias e para o estabelecimento de monopólios comerciais, o que resultou na implantação de uma rede de fluxos marítimos apoiada em portos e fortificações ao longo da rota entre Lisboa e as Índias, processo que foi iniciado antes da tomada de Constantinopla pelos turcos-otomanos em 1453.

A colonização do território brasileiro com sua enorme extensão geográfica obrigou os portugueses a adotar uma lógica territorial ${ }^{3}$, considerando de um lado as tentativas de outras nações de ocuparem parte do território descoberto, sobretudo franceses e holandeses, e do outro, encontrar uma atividade econômica para manter a nova colônia, na ausência da descoberta de metais preciosos, como no caso dos castelhanos.

\footnotetext{
${ }^{1}$ Esse artigo corresponde a texto revisto da Conferência apresentada no II Seminário Internacional SETEDANTE Estado, Território e Desenvolvimento: “A Governação dos Territórios", na Universidade de Santiago de Compostela, em 07/2015.

${ }^{2}$ Com exceção, sobretudo, de historiadores anglo-saxões como Boxer e Russell-Wood, entre outros e de geógrafos como Moraes.

${ }^{3}$ Posteriormente adotada também em Angola e Moçambique.
} 
O texto é dividido em duas partes: na primeira é examinada a situação do Brasil no contexto do Império colonial português, e em seguida são analisados, de forma resumida, os papéis do Estado e da Igreja Católica durante o período colonial no Brasil.

\section{A expansão marítima portuguesa}

Analisando a expansão colonial portuguesa uma série de fatos mostra uma continuidade, ao longo de séculos, de uma ocupação pontual ao longo de linhas de navegação, ou no máximo, de pontos fortificados em ilhas, no litoral do Oceano Atlântico e do Oceano Índico.

Observam-se dois movimentos iniciais: uma tentativa de ocupação de cidades no litoral marroquino e uma "descida" em direção ao sul, tanto através das ilhas do Atlântico, como do litoral africano.

Estabelecida a paz com Castela em 1411 os portugueses conquistaram Ceuta no norte do Marrocos (1415), com uma enorme frota de 200 navios, levando 19.000 combatentes e 1700 marinheiros (Saraiva, 1993, p. 131) ${ }^{4}$. Em seguida foram conquistadas Alcácer-Ceguer em 1458; Tânger e Arzila em 1471 e Aguer em 1505. O castelo de Safim foi construído em 1508 e em 1513 e 1514 foram ocupadas Azamor e Mazagão. Por outro lado, em 1513 os portugueses foram derrotados em Mamora 5 .

A partir de 1541 o movimento se inverteu: os portugueses começam a evacuar Arguer, Azamor e Safim, devido a pressão árabe-moura. Esta última chegou a ser sede de bispado. Entre 1549 e 1550 foram também evacuadas Arzila e Alcácer-Ceguer (Saraiva, op. Cit). Em 1578 na grande batalha de Alcácer Quibir, os portugueses, que contaram com 17.000 combatentes (sendo 5.000 mercenários estrangeiros), foram derrotados ${ }^{6}$ (Ibid., p. 174.), com a morte do rei $D$. Sebastião, o que teve como consequência a União Ibérica, com a passagem da coroa de Portugal para Filipe II da Espanha.

\footnotetext{
${ }^{4}$ Deve ser destacado que a conquista de Ceuta foi muito anterior à queda de Granada, último bastião árabemouro na Espanha (1492).

${ }^{5} \mathrm{O}$ que custou a morte de 4.000 portugueses (Russell-Wood, 2014, p. 99).

${ }^{6}$ Enders (1995, p. 36) informou que os combatentes foram transportados em 600 navios.
} 
O Marrocos deixou de ser prioridade em função das dificuldades de abastecimento por via marítima, pela resistência local e pelos novos interesses da Coroa portuguesa. Em 1640, com o fim da União Ibérica, Ceuta ficou sob domínio espanhol. Tânger foi doada aos ingleses em 1662 (Saraiva, 1993). Os portugueses abandonam a última praça do Marrocos, Mazagão, em 1769, quando os 2.000 habitantes da cidade foram cercados pelo enorme contingente de 120.000 árabes e berberes. Os habitantes da cidade foram transferidos para a Amazônia, uma rara transferência da população de uma cidade inteira para outro continente, com condições ecológicas bem diversas ${ }^{7}$. Esse último episódio marcou o único impacto direto da experiência marroquina para o Brasil. Por outro lado, a experiência da construção de fortificações em território hostil pode ter servido para aplicação no território brasileiro.

A posse do arquipélago da Madeira teria se dado em 1419. As ilhas foram doadas ao infante D. Henrique. As referidas ilhas foram desbravadas por um capitão donatário e o povoamento foi iniciado em 1433. Em 1424 os portugueses chegaram às ilhas Canárias e em 1426 aos Açores. Em 1439 foi iniciada a colonização dos Açores (Boxer, 2014). O açúcar produzido na Madeira começou a ser vendido na Inglaterra em 1456. Com o tratado de Alcáçovas, em 1479, os portugueses renunciaram às ilhas Canárias, único arquipélago atlântico na época que ficou sob o controle de Castela. Em 1514 Funchal, na ilha Madeira, foi elevada ao nível de Diocese (Saraiva, op. Cit).

As ilhas do Atlântico, vão servir de experimentação da produção do açúcar assim como do estabelecimento de capitanias hereditárias, que serão ampliadas no Brasil.

Em direção ao sul os portugueses chegaram em Arguim (atual Mauritânia) em 1443, quando D. Henrique recebeu o monopólio do Comércio da Guiné. No ano seguinte escravos da região foram vendidos em Lagos, dando início ao longo comércio de escravos africanos pelos europeus ${ }^{8}$. Uma feitoria foi estabelecida em torno de 1445 (Boxer, 2014), visando à aquisição de escravos, marfim e ouro, trazidos pelas caravanas, juntamente com a construção de uma fortaleza em 1448.

\footnotetext{
${ }^{7}$ Vidal (2005) registrou 2.092 pessoas embarcadas em 14 navios.

${ }^{8}$ Importante o destaque dado por Russell-Wood (2014) que o comércio de escravos africanos é anterior à chegada de Colombo na América.
} 
Em 1444 os portugueses alcançaram às ilhas do Cabo Verde ao largo do Senegal ${ }^{9}$ (Saraiva, op. cit).

Dez anos depois, em 1455 a Constituição Romanus Pontifex autorizou o rei de Portugal a escravizar "mouros e pagãos" (Enders, 1995, p. 25), o que incluía os africanos.

No ano seguinte, 1456, os portugueses chegaram mais ao sul, às ilhas Bijagos (na atual Guiné Bissau). Em 1462 começou o povoamento da ilha de Santiago, em Cabo Verde (Saraiva, 1993; Caldeira, 2013), cujos habitantes foram autorizados a comerciar com o continente. Podemos destacar aqui uma primeira relação entre uma colônia e territórios vizinhos sem passar pela metrópole.

Em 1469 foi passado um contrato do comércio da Guiné que foi arrendado por Fernão Gomes. Aqui também deve ser destacada uma primeira transferência do monopólio da Coroa para um particular.

Em 1470 os portugueses ocuparam as ilhas de São Tomé e Príncipe, bem mais ao sul ${ }^{10}$ (Boxer, op. Cit). A ilha de São Tomé chegou a ser o maior produtor de açúcar do mundo no século XVI (Russell-Wood, 2014). Em 1485 os comerciantes de São Tomé foram autorizados, por contrato, para realizar o comércio de escravos nos "rios da Guiné", o que tornou essas ilhas um centro de tráfico de escravos regional.

Em 1481 os portugueses, numa expedição de 10 caravelas e duas urcas, levaram 600 homens, incluindo artesões, soldados, comissários do comércio, membros do clero, marinheiros e pessoal feminino para trabalhos domésticos, assim como artilharia, alimentos e material para construir o forte ou castelo de São Jorge da Mina (Ballong-Wen-Mewuda, 1993, p. 58), o que confirma o interesse de fixação no litoral africano, numa área de produção de ouro. Em 1486 o pequeno povoado de Mina recebeu o status de cidade. Em 1503 foi construído um segundo forte em Axim. Além do interesse pelo ouro, o tráfico de escravos africanos vai ter uma importância fundamental devido à utilização intensiva na produção do açúcar brasileiro.

\footnotetext{
${ }^{9}$ Caldeira (2013) informou que as descobertas ocorreram no período 1456 a 1562.

${ }^{10}$ As ilhas ficam próximas ao litoral dos atuais estados da Guiné Equatorial e do Gabão. Em 1493 cerca de 2.000 crianças judias foram enviadas a São Tomé (Enders, op. cit).
} 
Em 1483 os portugueses estabeleceram contato com o reino do Congo (Boxer, op. Cit) e enviaram uma embaixada a capital do reino, Mbanza Congo, em 1491. Ao contrário da região da Mina, agora os portugueses encontraram um estado africano organizado, com estados suseranos no seu entorno ${ }^{11}$. Em 1485 contato foi estabelecido com o reino do Benim, situado na atual Nigéria ${ }^{12}$.

Em 1487 os portugueses realizaram a proeza da travessia do cabo da Boa Esperança, alcançando, portanto, o Oceano Índico (Boxer, 2014).

Só em 1494 foi assinado o Tratado de Tordesilhas, que estabeleceu a divisão do Mundo, na época, entre as coroas portuguesa e espanhola, ano da "descoberta" das Américas por Cristóvão Colombo.

Em 1498 a armada chefiada por Vasco da Gama chegou a Calicute, na Índia, objetivo principal dos portugueses, para tentar estabelecer o monopólio do comércio das especiarias (Saraiva, 1993).

A "descoberta"13 do Brasil em 1500 levou ao debate da intencionalidade ou não da viagem de Cabral e sua frota, que se dirigia para as Índias. No ano seguinte, uma expedição exploratória foi enviada ao litoral brasileiro e o comércio do pau brasil foi contratado com Fernão de Loronha, com a obrigação de implantar feitorias no litoral, ou seja, uma sessão de território a ser administrado por particular.

Os portugueses continuam investindo no litoral africano com a implantação de uma feitoria na ilha de Moçambique, porto de abastecimento das viagens para a Índia. O porto de Sofala foi tomado e um forte foi construído em 1505, buscando contato com a produção de ouro no vizinho Zimbábue. Quiloa e Mombaça, no atual Quênia, foram conquistadas no mesmo ano (Moraes, 2000). Em 1507 a ilha de Moçambique foi fortificada (Boxer, op. cit) e feitorias foram estabelecidas no interior, em Sena (1531) e Tete (1544).

\footnotetext{
${ }^{11}$ Presentes eram trocados entre os reis: em 1515 o rei do Congo enviou 78 escravos para D. Manoel (RussellWood, 2014, p. 42).

${ }^{12}$ Os portugueses em seguida exportaram escravos do Benim para Elmina para "atender a demanda africana por mão de obra em regiões florestais de extração de ouro e por carregadores [...]" (Russell-Wood, op. cit., p. 40)

${ }^{13}$ Segundo Saraiva "descobrir" tinha sentido na época de "obter informações sobre o que dantes era desconhecido" (op. cit., p. 146).
} 
Em 1533, Ribeira Grande, no Cabo Verde, foi elevada à cidade e tornou-se sede de um bispado. No ano seguinte, 1534, um segundo bispado foi criado em São Tomé com jurisdição sobre a terra firme, incluindo o Congo $^{14}$ (Enders, 1995).

Na Índia, em 1503, foi iniciada a fortificação de Cochin, ano que a Casa da Índia foi fundada em Lisboa. Dom Manuel acrescentou ao seu título o de "senhor da Guiné e da conquista, da navegação e do comércio da Etiópia, Arábia, Pérsia e Índia" (Boxer, 2014, p. 52; Saraiva, 1993, p. 160). Um Vice-Rei da Índia foi nomeado em 1505, confirmando a importância e a prioridade dessas conquistas em comparação ao abandono do litoral brasileiro no mesmo período. Goa foi conquistada em 1510 (Boxer, op. cit.; Saraiva, op. cit). Uma feitoria foi estabelecida em Chaul em 1516, cujo forte foi concluído em 1524. Em 1534 Bassaim foi cedida aos portugueses e Goa foi elevada ao nível de bispado, passando ao de Arcebispado em 1557, confirmando a importância do Oriente nesse período. Em 1559 Damão foi conquistada. Em pouco mais de meio século os portugueses tinham estabelecido uma rede de cidades no subcontinente indiano.

As ambições portuguesas não se restringiam a esse subcontinente. O chamado "Estado da Índia" ia desde o Cabo da Boa Esperança e o golfo pérsico até o Timor e o Japão (Boxer, op. cit.; Saraiva, op. cit.; Enders, 1995). Em 1513 os portugueses atacaram Aden, na península arábica, mas sofreram derrota em Mamora, dois anos depois. Ormuz, na atual Pérsia, foi tomada em 1515, mas foi retomada pelos persas em 1622. Em paralelo, em 1505, ocuparam parte do litoral do Ceilão. Em 1511 submeteram a cidade de Malaca (na atual Malásia) e chegaram na ilha Ternate, nas Molucas (na atual Indonésia), já em áreas que seriam de Castela. Pelo tratado de Saragoça os portugueses tomaram posse das ilhas Molucas, em 1529. Porém em 1575 o sultão local recuperou a ilha Ternate (Boxer, op. cit).

As relações com o Japão foram estabelecidas em 1543 e a feitoria de Nagasáqui foi fundada em 1571. Apenas em 1588 foi criada a primeira diocese no Japão. Em 1639 os portugueses foram expulsos do Japão pelas autoridades locais.

Em 1557 os portugueses receberam do governo chinês a península de Macau (Boxer, 2014), cuja diocese foi autorizada em 1575 (Saraiva, 1993). Um comércio foi estabelecido entre as

\footnotetext{
${ }^{14}$ Segundo Alencastro ((2000), em São Tomé a Irmandade do Rosário dos Negros (1526) é anterior a mesma irmandade de Salvador (1581).
} 
duas feitorias asiáticas. Em pouco mais de meio século os portugueses tinham estabelecido uma rede comercial que se estendia das ilhas do Atlântico até a China e o Japão, com seus principais estabelecimentos implantados no subcontinente indiano.

Só entre 1530 e 1533 a expedição comandada por Martim de Souza foi enviada ao litoral brasileiro e a primeira vila, São Vicente, foi fundada em 1532, quando foram implantados os primeiros engenhos de açúcar. Em 1534 foram criadas as capitanias hereditárias no Brasil, seguindo o modelo das ilhas do Atlântico, porem em uma escala territorial bem mais ampla. A elevação de vice-reinado na Índia e a implantação no período dos bispados de Funchal, de Goa, de Cabo Verde e de São Tomé, mostram a pouca importância inicial dada ao território brasileiro pelos portugueses.

Devido ao fracasso da maior parte da experiência das capitanias hereditárias, em 1549 a Coroa portuguesa implantou o Governo Geral no Brasil e fundou a cidade de Salvador, em um processo semelhante à implantação do castelo da Mina. Dois anos depois foi criado o bispado em Salvador, porém subordinado ao de Funchal.

Apesar do estabelecimento do Governo Geral, os franceses desembarcaram no Rio de Janeiro, em 1555, com a pretensão de criar uma "França Antártica", mas foram derrotados e expulsos cinco anos depois. Em 1567 foi fundada a cidade de São Sebastião do Rio de Janeiro. Em 1611 os franceses tentaram implantar a "França Equinocial" no Maranhão, mas também foram expulsos em 1615.

O período da União Ibérica (1580-1640) foi muito importante para o Brasil e teve consequências trágicas para Império português, tendo em vista os ataques realizados em quatro continentes pela armada dos comerciantes e do Estado dos Países Baixos, que já estavam em guerra contra a Espanha.

Os portugueses ocuparam o Pará em 1616, com a implantação do forte do Presépio, que deu origem a cidade de Belém, e passaram a controlar a foz e a enorme bacia do rio Amazonas, territórios muito além da linha das Tordesilhas. Em 1621 foi criado o Estado do Maranhão, independente do Estado do Brasil até 1652. Essa divisão, em parte, era resultado das dificuldades de navegação a vela entre a região norte e as regiões nordeste e sul do Brasil. 
Na África os portugueses enviaram embaixada ao N'Gola, na atual Angola, em 1560. O primeiro capitão donatário foi nomeado para Angola em 1570, sendo Luanda fundada em 1575 (Boxer, 2014). O Governo Geral foi implantado em 1592, quando terminaram as capitanias hereditárias nesse território (Russell-Wood, 2014).

Em 1570 os jagas foram derrotados quando atacaram a capital do Congo, agora denominada São Salvador, com ajuda de tropas portuguesas. Em 1587 a cidade foi elevada a sede de bispado.

Na Guiné os portugueses estabeleceram uma feitoria em Cacheu em 1588 (Caldeira, 2013) e a elevaram a categoria de cidade em 1600.

O território restrito sob a ocupação portuguesa em Angola foi ampliado com a fundação de Benguela em 1617 (Saraiva, 1993), e o bispado de São Salvador no Congo foi transferido para Luanda em 1623, indicando a maior importância de Angola do que o Congo para os portugueses.

A partir desse período há um forte paralelismo entre as ações portuguesas no Brasil e na região Congo-Angola, complementares pela produção do açúcar e pelo tráfico de escravos.

No Moçambique os portugueses foram atacados em Dambarare em 1593 e Mombaça foi cercada pelos árabes em 1596. Foram enviados 400 soldados da Bahia para socorrer essa cidade em 1700, mas o litoral dos atuais territórios de Quênia e Tanzânia já tinha sido evacuado entre 1696-1698 (Enders, 1995). O envio de tropas do Brasil para a África mostra a interdependência das regiões do império.

Em 1598 e 1599 começaram os ataques holandeses a São Tomé e em 1607 e 1608 eles também tentaram conquistar Moçambique (Boxer, 2014). Em 1609 os holandeses tomaram o Ceilão (Saraiva, 1993). Em 1622 atacaram Macau, na China, e foram repelidos (Boxer, op. cit). Em 1624 os holandeses invadiram Salvador da Bahia e foram expulsos no ano seguinte, mas voltaram em 1630 quando ocuparam Pernambuco, com um efetivo de 7.000 homens (Marcadé em Mauro, 1991, p. 25). Em 1637 os holandeses ainda conquistaram os fortes da Mina e de Axim, no atual Gana e limitaram o comércio dos portugueses aos portos de Grande Popo, Ajudá, Jaquin e Apa (Enders, 1995), através do pagamento em fumo produzido na Bahia. 
Em 1640 acaba a União Ibérica com a restauração da Coroa portuguesa, mas os holandeses continuaram suas ações: ainda conquistaram São Tomé, Luanda e Benguela em 1641, com expedição enviada de Recife, com cerca de 3.000 homens em 21 navios ${ }^{15}$, controlando assim o tráfico de escravos entre a África e o Brasil. Os holandeses também ocuparam a longínqua Malaca no mesmo ano (Saraiva, 1993).

Com a restauração da coroa portuguesa foi nomeado o primeiro Vice-Rei no Brasil em 1640, um século e meio após o vice-reinado ter sido implantado na Índia.

Em 1644 foi autorizado o tráfico negreiro direto entre o Brasil e a Costa da Mina (Verger, 1987, p. 21 e 56), devido à ocupação holandesa de Angola. No ano seguinte, 1645, foi enviada força expedicionária da Bahia para socorrer Angola, mas a mesma foi derrotada pelos canibais jagas (Boxer, op. cit., p. 241) ${ }^{16}$. Em 1648 aconteceu um evento excepcional: Angola foi tomada por uma expedição luso-brasileira, com 15 navios, com uma estimativa de 1.000 a 2.000 homens, que saiu do Rio de Janeiro comandada por Salvador de Sá (Boxer, op. cit). Os holandeses, enfraquecidos com a guerra com a Inglaterra, iniciada em 1652, também foram derrotados e expulsos do Brasil por tropas luso-brasileiras em 1654 (Ibid, p. 415), após 24 anos de ocupação.

Em 1652, a Relação, Tribunal de Justiça, foi reestabelecido em Salvador da Bahia com autoridade sobre Angola e São Tomé, extrapolando, portanto, o território brasileiro (Schwartrz, S. in Silva, 1994). Como exemplo, em 1744, sete líderes da revolta em São Tomé foram julgados em Salvador (Vasconcelos, 2002). O arcebispado da Bahia foi fundado em 1676 com jurisdição sobre os bispados de São Tomé e Luanda (até 1717) (Mauro, 1977; Enders, 1995). Em 1707 o bispo de Angola participou de Sínodo organizado pelo Arcebispo de Salvador. Essas novas medidas mostram uma organização territorial que extrapola o território brasileiro, e confirma a elevação de status da cidade do Salvador ${ }^{17}$.

Outro fato excepcional foi o do Vice-Rei do Brasil, D. Vasco de Mascarenhas, ordenar a fundação de feitoria e construção de forte em Ajudá, no atual Benim, em 1721, com

\footnotetext{
${ }^{15}$ Boxer (1973) acrescentou que índios tamoios participaram das tropas enviadas pelos holandeses. Alencastro (2000, p. 124) estimou um total de 200 índios potiguares.

${ }^{16}$ Dos 107 soldados sobreviveram apenas quatro (Alencastro, op. cit., p. 225).

${ }^{17}$ Devido a dimensão do Império, Goa passou a administrar a região de Moçambique.
} 
aprovação do rei local ${ }^{18}$, reforçando os vínculos entre o Brasil e o continente africano. Em 1743 esse forte foi destruído pelas tropas do rei do Daomé. O liberto africano João de Oliveira, voltou para a Costa da Mina em 1733 e abriu Porto Novo (Ardra) e Onim (Lagos) como portos de tráfico (Caldeira, op. cit), ampliando a relação direta entre a África ao norte do Equador e a Bahia. Em 1807 os portugueses tinham abandonado o reconstruído forte de Ajudá, que ficou sob os cuidados do brasileiro Francisco Felix de Souza, que passou a dominar o tráfico local, monopolizando o tráfico originário do Daomé (Silva, 2013; Enders, op. cit).

Em 1762 tropas foram enviadas da Bahia contra os sobas em Angola (Vasconcelos, op. cit), registrando uma relação também com as áreas ao sul do Equador.

Estados africanos enviaram embaixadas para Salvador com a intenção de manter os monopólios da exportação de escravos: do rei do Daomé em 1750, 1805 e 1811 para Salvador e em 1795 para Lisboa; do rei de Onim para Salvador em 1770 e 1807; e do Rei de Ardra, em 1810, para a mesma cidade (Verger, 1987).

Na Índia Bombaim foi doada aos ingleses, fortalecendo a aliança entre os dois países em 1662 (Saraiva, 1993) e os holandeses ainda conquistam Cochin, no ano seguinte. Os portugueses perderam ainda para os maratas indianos as cidades de Baçaim e Chaul em 1739 e 1740, reduzindo ainda mais suas posições na Índia. Em 1750, no período pombalino a costa oriental da África, incluindo Moçambique, foi desligada da jurisdição de Goa, confirmando a redução da importância da Índia portuguesa.

$\mathrm{Na}$ África os congoleses foram derrotados pelos portugueses na batalha d'Ambouila em 1665 (Boxer, 2014), e o reino do Congo tornou-se uma espécie de protetorado português (Russell-Wood, 2014). O reino de Ndongo, na atual Angola, caiu sob o domínio português em 1671. Em Angola, em 1698 Luanda ganha status de cidade (Ibid). Entre 1764 e 1772, o governador Francisco Coutinho fundou uma academia para formação de engenheiros, implantou uma fundição de ferro e deu início à construção naval, numa tentativa de diversificar a economia baseada na exportação de escravos.

\footnotetext{
${ }^{18}$ Enders, op. cit.. Caldeira (2013, p. 67) informou que o forte foi financiado pelos traficantes de escravos da Bahia.
} 
Foram criadas as companhias de Cacheu e Rios da Costa da Guiné (1676), de Cacheu e Cabo Verde (1690) e a Real da Guiné e Índias (1693), essa última para fornecer escravos ao assiento espanhol (até 1701). A capitania de Bissau foi restabelecida em 1753.

A capitania geral de Moçambique foi criada em 1752 (Boxer, op. cit) e foi estabelecido um sistema enfiteutico de "prazos", que deu origem a senhores quase autônomos da Coroa portuguesa, que mantinham tropas formadas de escravos armados (Capela, 1995). Lourenço Marques foi fundada apenas em 1782 (Saraiva, 1993). Também foi iniciada a construção naval (brigues) em Moçambique.

Em 1778 os portugueses cederam aos espanhóis as ilhas de Fernando Pó e Ano Bom (atual Guiné Equatorial), em troca de territórios no sul do Brasil (Ibid).

Os portugueses fundaram a Colônia do Sacramento em 1680 numa tentativa de chegar ao rio da Prata, no atual Uruguai, mas perderam a mesma em 1778, quando recuperaram a região de Santa Catarina e Rio Grande do Sul na referida troca de ilhas africanas. Mas o evento mais importante do período foi a descoberta do ouro nas minas gerais, em 16981699, tornado, definitivamente o Brasil a principal colônia portuguesa (Mauro, 1977) ${ }^{19}$, ao tempo que o interior do território brasileiro ia sendo ocupado de forma sistemática. Em 1729 também foram descobertos diamantes na região.

Na Amazônia o forte de São José do Rio Negro foi fundado em 1669, seguido pelo de Macapá em 1764. O Estado do Grão-Pará e Maranhão foi criado em 1751, separado do Estado do Brasil (até 1774). A fundação da Companhia Geral do Grão-Pará e Maranhão foi voltada para atuar na Guiné e Cabo Verde em 1755 (até 1778) e a Companhia de Pernambuco e Paraíba para atuar na Costa da Mina e em Angola. A Companhia obteve o governo de Cabo Verde, em 1759 (Enders, 1995): ou seja, trata-se do caso inédito de controle de governo colonial por uma companhia comercial.

Como consequência da importância do escoamento da produção do ouro e dos interesses e conflitos portugueses no rio da Prata, a capital do Brasil foi transferida de Salvador para o Rio de Janeiro em 1763, ou seja, um pouco mais de dois séculos depois de sua fundação.

\footnotetext{
${ }^{19} \mathrm{Em} 1699$ foram enviados $500 \mathrm{~kg}$. de ouro para Lisboa. Em 1720 o total alcançou 25 toneladas (Saraiva, op. cit., p. 240)
} 
Em 1808, finalmente, diante da invasão das tropas napoleônicas, o príncipe D. João transferiu a sede do Império de Lisboa para o Rio de Janeiro. Pela primeira vez na história, uma colônia torna-se sede de um império, o que vai resultar no fim do status colonial e na independência do Brasil em 1822. Os reis do Benim e de Onim foram os primeiros soberanos a reconhecer a independência do Brasil (Silva, 2013). Só em 1825 o governo português reconheceu independência, mediante indenização. Os vínculos do tráfico de escravos entre o continente africano e o Brasil são demonstrados pelo reconhecimento da independência do Brasil por dois estados africanos assim como pelo interesse demonstrado por traficantes angolanos e moçambicanos de vincular essas colônias ao novo estado independente.

O que podemos destacar depois da complexidade de eventos em diferentes contextos históricos e geográficos, é a transformação de um império mercantil implantado por uma série de feitorias, fortes e cidades portuárias, em um império cuja base principal é o imenso território brasileiro, que só foi possível consolidá-lo com a implantação da produção de açúcar voltada para a exportação, em grandes propriedades, baseada no trabalho escravo, cujas repercussões sobre a sociedade e economia brasileiras foram fundamentais até o momento presente.

\title{
2. A governação do território brasileiro
}

\begin{abstract}
Se vamos à essência de nossa formação, veremos que na realidade nos constituímos para fornecer açúcar, tabaco, alguns outros gêneros; mais tarde ouro e diamantes; depois algodão, e em seguida café, para o comércio europeu. Nada mais que isto. E com tal objetivo, objetivo exterior, voltado par fora do país e sem atenção a considerações que não fossem o interesse daquele comércio, que se organizarão a sociedade e a economias brasileiras. Tudo se disporá naquele sentido: a estrutura, bem como as atividades do país (Prado Jr., 2000, p. 20).
\end{abstract}

Os portugueses deram origem a uma nova forma de organização social e territorial: uma colônia voltada para produzir e exportar mercadorias de interesse dos mercados europeus, como o açúcar. Essa orientação foi agravada pela concentração da propriedade fundiária e, sobretudo, pela utilização sistemática, em todo o território, do trabalho escravo. 
Como governar um complexo Império disperso em quatro continentes? Como passar da lógica de redes para a lógica territorial? A Coroa portuguesa tentou vários expedientes, sendo um dos principais a criação do Conselho Ultramarino em 1642. Como vimos, as capitanias hereditárias foram experimentadas nas ilhas do Atlântico e no continente africano. O governo geral também foi experimentado na África. O Estado da Índia foi iniciado com a nomeação de um Vice-Rei.

Mas no Brasil, com um imenso território, com fronteiras imprecisas, e com o estabelecimento do sistema escravista, além da gestão das outras partes do Império, era necessário controlar e colonizar a colônia. Foram realizadas tentativas de centralização e descentralização administrativa, como nas experiências de criação de Estado separado do Brasil na região amazônica, devido a maior acessibilidade com Lisboa, assim como nas experiências de separação de governos do norte (sede em Salvador) e do sul da colônia (sede no Rio de Janeiro).

Vamos destacar nesta segunda parte o papel do Estado, em seus diferentes níveis e o papel da Igreja no governo do território, com ênfase no período colonial.

\section{O Estado}

Consideramos o papel do Estado no controle do território da América portuguesa em diferentes níveis: a Coroa portuguesa e suas instituições; os representantes da Coroa no Brasil; e os representantes da administração local: o papel importante das Câmaras.

Segundo Prado Junior para a administração metropolitana o Brasil era composto de várias colônias, administradas pelo referido Conselho Ultramarino (Prado Jr., 2000, p. 313). Os mesmos referenciais jurídicos de Portugal se aplicavam a colônia: Ordenações Afonsinas (1467), Manuelinas (1514-1521) e Filipinas (1603), que tiveram continuidade até 1917, já no período republicano.

A primeira divisão territorial do Brasil foi experimentada pelas capitanias hereditárias, a partir de uma divisão do litoral em faixas de cerca de 50 léguas de comprimento que ficaram a cargo dos donatários, que foram responsáveis pela sua ocupação, colonização e 
desenvolvimento. Essa experiência em geral não foi satisfatória, com a exceção de duas capitanias: Pernambuco e São Vicente.

A Coroa passou então a formar um governo geral, sediado em Salvador, através da fundação e implantação da cidade (1549). A capitania foi adquirida dos herdeiros do primeiro donatário, derrotado e eliminado pelos autóctones. O Governo Geral foi implantado em paralelo as demais capitanias hereditárias.

Os governadores faziam doações de sesmarias aos colonos importantes, sobretudo membros da nobreza com algumas exigências para a implantação de engenhos de açúcar. $\mathrm{Na}$ produção de açúcar, portanto, os maiores investimentos eram voltados para a construção de engenhos e a compra de escravos, pois as terras eram recebidas em sesmarias. Em seguida as sesmarias começaram a ser subdivididas sendo arrendadas aos pequenos colonos.

Com a doação de sesmarias nas áreas interioranas de criação de gado, no Sertão, propriedades gigantescas ficaram nas mãos de famílias poderosas, que criaram conflitos com os missionários e que o Estado não tinha meios de controle eficiente. Algumas propriedades atingiram 260 léguas (1.560 km), como a Casa da Torre, da família de Garcia d'Ávila, ou 160 léguas (960 km), como a Casa da Ponte, ambas ao longo do rio São Francisco (Freire, 2000, p. 34-35, citando Antonil). Esses abusos foram limitados a partir de 1729, com provisão que proibiu a doação de sesmarias com mais de três léguas de comprimento e uma de largura. Também a partir de 1780 os sesmeiros passaram a condição de simples foreiros, perdendo a propriedade plena (Ibid).

O governador geral tinha como prioridade a defesa da colônia. Os militares eram divididos em tropas de linha (profissional, em geral portugueses); milícias (tropas auxiliares formadas pelos colonos e segregadas por cor); e corpos de ordenanças (o resto da população) (Prado Jr., op. cit). Com o estabelecimento da aula de fortificações em Salvador, em 1699, foi dado início a formação de engenheiros militares na Colônia, um dos quais, José Antonio Caldas, construiu um forte na ilha de São Tomé, na África.

A implantação de um sistema de fortificações nas cidades e portos do litoral, como Salvador (1549), Rio de Janeiro (1567), assim como Paraíba (1585), Natal (1599), São Luís (1612), 
Belém (1616) e Sacramento (1680) (Araujo, R. in Moreira, 1989), teve continuidade com o estabelecimento de fortificações ao longo das fronteiras interiores, sobretudo no século XVIII, em São Joaquim do Rio Branco, São Gabriel da Cachoeira, São Joaquim de Marabitenas e São Francisco Xavier da Tabatinga, na Amazônia nos anos 1750-1760; Macapá foi fortificada em 1764 e na longínqua capitania de Mato Grosso foram implantados os fortes de Coimbra e Príncipe da Beira (1775-1776) (Lemos, C. in Moreira, 1989).

A Coroa Portuguesa ordenou a construção de navios de guerra no Arsenal de Salvador. Dois exemplos: em 1659 foi lançada a nau Capitania Real, com 1.000 toneladas e em 1716 foi construído um navio com 84 canhões e com capacidade para 700 homens (Vasconcelos, no

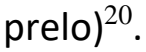

O judiciário era composto pelas Relações da Bahia e do Rio de Janeiro. A jurisdição das Comarcas era de responsabilidade dos ouvidores.

A Junta da Fazenda era o principal órgão da administração fazendária e o principal tributo era o dízimo. A arrecadação era normalmente efetuada por contratantes. Com a produção do ouro, o quinto (20\%) passou a ser a principal forma de arrecadação nas áreas mineradoras.

As capitanias eram divididas em comarcas (divisões judiciais), que eram por sua vez divididas em termos, cujas sedes estavam em cidades e vilas. Os termos eram divididos por freguesias.

No nível municipal, nas vilas e nas cidades, os Senados das Câmaras tiveram um papel fundamental de gestão da vida cotidiana através de posturas, assim como na doação de terras (datas) nos seus territórios (termos). O mesmo sistema funcionou em todo império português. Compunha-se de um juiz-de-fora (nomeado pelo rei) ou dois juízes ordinários, três vereadores e um procurador. Também havia ainda um juiz do povo e dois representantes dos mestres artesãos (1581-1713).

A Câmara de Salvador teve um papel destacado na formação da nacionalidade brasileira e na tentativa de ordenamento da cidade. Alguns exemplos podem ser destacados: depois da

\footnotetext{
${ }^{20}$ No Rio de Janeiro Salvador de Sá construiu um dos maiores navios da época: o Padre Eterno, com 2.000 toneladas e 114 canhões. Em 1665 o navio participou da frota do Brasil (Mauro, 1989, I, p. 65).
} 
invasão holandesa em 1625 os membros da Câmara se reuniram para reconstituir de memória as posturas de ordenamento da cidade, tendo em vista que os holandeses tinham destruído todos os documentos existentes. Uma das consequências foi a ocupação das terras da sesmaria da Câmara sem pagamento de foro. Em 1671 os membros da Câmara solicitaram diretamente ao rei de Portugal "reparar Decreto" que impedia que os nascidos no Brasil fossem desembargadores, considerando o que parecia "huma ofensa que Vossa Magestade faz aos filhos deste Estado e principalmente aos daBahia" (Vasconcelos, no prelo). Para eles, escrevendo em nome do conjunto dos brasileiros, não deveria haver discriminação entre os nascidos no Brasil e os reinóis.

\section{A Igreja}

A Igreja Católica teve um papel fundamental na questão do controle do território no Brasil colonial. Em alguns casos, ela teve mais importância que o próprio Estado.

Devemos lembrar, em primeiro lugar, que o regime do Padroado da Ordem de Cristo foi passado para a Coroa portuguesa em 1515. Como as terras brasileiras estavam sob a jurisdição da Ordem de Cristo e sendo o Rei de Portugal o seu representante, a cobrança de dízimos ficou sob a administração da Coroa, que ao mesmo tempo era responsável pela manutenção da Igreja e do clero secular na colônia.

O primeiro bispado de Salvador foi implantado em 1551, e teve sua jurisdição sobre parte do território brasileiro (o Norte ficou vinculado a Lisboa, devido às dificuldades de navegação). O arcebispado, implantado em 1676, incluía também territórios africanos, como Angola e São Tomé e Príncipe, já comentados.

A importância do arcebispado de Salvador pode ser destacada com a reunião do Sínodo em 1707, que aprovou as Constituições Primeiras do Arcebispado da Bahia. O referido sínodo contou com a presença do bispo de Angola, enquanto que o do Rio de Janeiro não compareceu por estar doente. As constituições estabeleceram normas para a Igreja e para a sociedade, ao tempo que o Estado não dispunha de documento específico para a América Portuguesa. Entre as regras, podem ser destacadas as discriminações étnicas da época, através da proibição do sacerdócio de candidatos que "tem parte da nação Hebrea, [...] ou 
de outra qualquer infecta [...] ou de Negro ou Mulato"; da necessidade do candidato ter um patrimônio, que "renda ao menos cada ano vinte e cinco mil réis [...]". Quanto aos requerimentos urbanísticos foi determinado que "As Igrejas se devem fundar, e edificar em lugares decentes, e acommodados"; e, sobretudo, normas foram adaptadas à sociedade escravista: "Não gozão de immunidade da Igreja [...] o escravo (ainda que seja Christão) que fugir a seu senhor para se livrar do captiveiro" (Vide, S. in Vasconcelos, no prelo).

Um destaque especial do papel da Igreja nas cidades foi o da divisão administrativa a partir do estabelecimento dos territórios paroquiais, que até hoje servem de base aos subdistritos da administração municipal.

As ordens religiosas também tiveram um papel fundamental, tanto no ensino, como no papel missionário junto aos Índios, sobretudo na implantação de aldeias. As ordens também receberam grandes sesmarias, como os jesuítas, que utilizaram o trabalho escravo e experimentaram a implantação de plantas exóticas originadas das Índias e do continente africano.

Houve conflitos entre o Estado e a Igreja: conventos não foram autorizados na região de Minas Gerais (Martinière in Mauro, 1991). Os jesuítas foram expulsos em 1759, em parte devido aos conflitos sobre as áreas missionárias no sul do Brasil ${ }^{21}$.

\section{Conclusões}

Procurei inserir a discussão da colonização do território brasileiro em um contexto mais amplo, o do Império colonial português, tendo em vista as experiências em governança realizadas em outros espaços e em períodos anteriores ao "descobrimento" do Brasil. Governadores, vice-reis, e outros funcionários de grau elevado exerciam suas autoridades em diferentes partes do território do império. Um exemplo excepcional: o mulato João Fernandes Vieira, nascido em Madeira, residiu em Pernambuco durante a ocupação holandesa. Ele enriqueceu com o comércio com os holandeses, mudou de lado durante a

\footnotetext{
${ }^{21} \mathrm{O}$ poder dos jesuítas pode ser mensurado pelo fato de que o Provincial da ordem tinha uma fragata para seus deslocamentos (Mauro, 1977).
} 
guerra e participou das batalhas para a expulsão dos invasores, e recebeu, como prêmio, o governo de Angola (Raminelli, A. in Vainfas, 2000).

A própria expansão do território brasileiro muito além da linha do Tratado de Tordesilhas, se deu pela iniciativa dos brasileiros, seja de mestiços de índios, como os bandeirantes, mas também pelo trabalho das ordens religiosas, como na ocupação da Amazônia e do sertão brasileiro, regiões em que o Estado tinha menor domínio.

O tráfico de escravos entre a África e o Brasil, ao longo de três séculos e meio, extrapolando o período colonial, é certamente, o maior exemplo de que não se pode estudar o Brasil de forma isolada, e que suas consequências, no longo prazo, resultaram numa das nações mais desiguais do Mundo.

\section{Referências bibliográficas}

ALENCASTRO, Luiz F. O Trato dos Viventes: formação do Brasil no Atlântico Sul. São Paulo: Companhia das Letras, 2000.

BALLONG-WEN-MEWUDA, J. Bato'ora. São Jorge da Mina 1482-1637. Lisboa: Fondation C. Gulbenkian; Paris: EHESS, 1993.

BOXER, Charles R. Portuguese Society in the Tropics. The Municipal Councils of Goa, Macao, Bahia, and Luanda, 1510-1800. Madison, Univ. of Wisconsin Press, 1965.

BOXER, Charles R. O Império Marítimo Português 1414-1825. Lisboa: Eds. 70, 2014 [1969].

BOXER, Charles R. Salvador de Sá e a luta pelo Brasil e Angola, 1602-1686. São Paulo: Nacional; Edusp, 1973 [1952].

CALDEIRA, Arlindo Manuel. Escravos e traficantes no Império Português. Lisboa: A Esfera dos Livros, 2013.

CAPELA, José. Donas, Senhores e Escravos. Porto: Afrontamento, 1995.

ENDERS, Armelle. Histoire de l'Afrique Lusophone. Paris: Chandeigne, 1995.

ENDERS, Armelle. Nouvelle Histoire du Brésil. Paris: Chandeigne, 2008.

FREIRE, Felisbello. Historia Territorial do Brazil. Salvador: S.C.T.; IGHB, 2000 [1906].

JOHNSON, H.; SILVA, M. B. N. (Org.) O Império Luso-Brasileiro (1500-1620). Lisboa: Estampa, 1992.

MAURO, Frédéric. Portugal, o Brasil e o Atlântico (1570-1670). Lisboa: Estampa, 1989 [1957].

MAURO, Frédéric. Le Brésil du XVe a la fin du XVIIle siècle. Paris: S.E.D.E.S., 1977.

MAURO, Frédéric. (Org.) O Império Luso-Brasileiro (1620-1750). Lisboa: Estampa, 1991.

MORAES, Antonio Carlos R. Bases da Formação Territorial do Brasil. São Paulo: Hucitec, 2000.

MORAES, Antonio Carlos R. Território e História no Brasil. São Paulo: Annablume, 2005. 
MOREIRA, Rafael (dir.) História das Fortificações Portuguesas no Mundo. Lisboa: Alfa, 1989.

PRADO Júnior, Caio. Formação do Brasil Contemporâneo. São Paulo: Brasiliense; Publifolha, 2000 [1942].

RUSSELL-WOOD. Histórias do Atlântico português. São Paulo: Unesp, 2014 [2009].

SARAIVA, José Hermano. História de Portugal. Lisboa: Alfa, 1993.

SILVA, Alberto da Costa e. Um rio chamado Atlântico: a África no Brasil e o Brasil na África. Rio de Janeiro: Nova Fronteira; UFRJ, 2013.

SILVA, Maria Beatriz N. da. (Org.) O Império Luso-Brasileiro (1750-1822). Lisboa: Estampa, 1986.

SILVA, Maria Beatriz N. da (Org.) Dicionário da História da Colonização Portuguesa no Brasil. Lisboa: Verbo, 1994.

VAINFAS, Ronaldo (org.) Dicionário do Brasil Colonial (1500-1808). Rio de Janeiro: Objetiva, 2000.

VASCONCELOS, Pedro de A. Salvador: transformações e permanências (1549-1999). Ilhéus: Editus, 2002.

VASCONCELOS, Pedro de A. Salvador: transformações e permanências (1549-1999). 2a edição revisada e ampliada. Salvador: Edufba, no prelo.

VERGER, Pierre. Fluxo e Refluxo do tráfico de escravos entre o golfo do Benin e a Bahia de Todos os Santos: dos séculos XVII a XIX. São Paulo: Currupio, 1987.

VIDAL, Laurent. Mazagão. La ville qui traversa l'Atlantique. Du Maroc à l'Amazonie (1769-1783). Paris: Aubier, 2005.

http://www.japassei.pt/pt/1-1-o-imperio-portugues-no-seculo-xviii 